\title{
SCIENTIFIC REPORTS

\section{Isolation and characterization of nutrient dependent pyocyanin from Pseudomonas aeruginosa and its dye and agrochemical properties}

Savitha DeBritto ${ }^{1,2}$, Tanzeembanu D. Gajbar ${ }^{1}$, Praveen Satapute ${ }^{1}$, Lalitha Sundaram ${ }^{3}$, Ramachandra Yarappa Lakshmikantha ${ }^{4}$, Sudisha Jogaiah ${ }^{1^{*}} \&$ Shin-ichi Ito ${ }^{5,6^{*}}$

Pyocyanin is a blue green phenazine pigment produced in large quantities by active cultures of Pseudomonas aeruginosa, with advantageous applications in medicine, agriculture and for the environment. Hence, in the present study, a potent bacterium was isolated from agricultural soil and was identified morphologically and by $16 \mathrm{~S}$ rRNA sequencing as $P$. aeruginosa (isolate KU_BIO2). When the influence of nutrient supplements in both King's $A$ and Nutrient media as amended was investigated, an enhanced pyocyanin production of $2.56 \mu \mathrm{g} \mathrm{ml}^{-1}$ was achieved in King's A medium amended with soya bean followed by $1.702 \mu \mathrm{g} \mathrm{ml}^{-1}$ of pyocyanin from the nutrient medium amended with sweet potato. Purified pyocyanin was characterized by UV-Vis Spectrophotometer and FourierTransform Infrared spectroscopy (FTIR). Furthermore, Liquid Chromatography Mass Spectrum (LCMS) and Nuclear Magnetic Resonance (NMR) confirmed its mass value at 211 and as $\mathrm{N}-\mathrm{CH}_{3}$ protons resonating at $3.363 \mathrm{ppm}$ as a singlet respectively. The isolated pyocyanin displayed remarkable dye property by inducing color change in cotton cloth from white to pink. Lastly, the antifungal activity of test pyocyanin showed inhibition of growth of rice blast fungus, Magnaporthe grisea and bacterial blight of rice, Xanthomonas oryzae at concentrations of 150 and 200 ppm, respectively. Thus, this investigation provides evidence for diverse actions of pyocyanin which are nutrient dependent and are capable of acting on a large scale, by utilizing microbes existing in agriculture wastes, and thus could be used as an alternative source in the making of natural textile dyes with strong durability and a broad spectrum of ecofriendly agrochemicals.

Microorganisms are biological agents which help to solve many problems related to health, agriculture and the environment ${ }^{1-3}$. Microorganisms have been the study at interest in recent years because of production of novel secondary metabolites ${ }^{4}$. These metabolites exhibit antimicrobial, antiviral or antitumor as well as anticoagulant properties, and the production of secondary metabolites may have evolved as an alternative strategy to switching off metabolic pathways by various control mechanisms $s^{5-7}$. Products of secondary metabolism, such as pigments, could also be of considerable selective advantage since they could eliminate possible microbial competitors ${ }^{8}$.

Natural pigments have been obtained and used since long ago, but interest in them has decreased due to toxicity problems. Hence, pigments from microbial sources are good alternatives for various applications ${ }^{9,10}$. Pseudomonas aeruginosa is one of the most commercially valuable organisms, many of which are responsible for producing soluble pigments like pyocyanin (blue), pyoveridin (yellow-green), pyorubin (red) and pyomelanin (brown $)^{11}$. P. aeruginosa produces pyocyanin (N- methyl- 1- hydroxyphenazine) which is a water soluble

${ }^{1}$ Laboratory of Plant Healthcare and Diagnostics, P.G. Department of Biotechnology and Microbiology, Karnatak University, Dharwad, Karnataka, 580003, India. 'Division of Biological Sciences, School of Science and Technology, The University of Goroka, Goroka, 441, Papua New Guinea. ${ }^{3}$ Department of Botany, Periyar Palkalai Nagar, Periyar University, Salem, 636011, Tamil Nadu, India. ${ }^{4}$ Department of Biotechnology and Bioinformatics, Kuvempu University, Jnanasahyadri, Shivamogga, 577451, India. ${ }^{5}$ Laboratory of Molecular Plant Pathology, Department of Biological and Environmental Sciences, Graduate School of Sciences and Technology for Innovation, Yamaguchi University, Yamaguchi, 753-8515, Japan. ${ }^{6}$ Research Center for Thermotolerant Microbial Resources (RCTMR), Yamaguchi University, Yamaguchi, 753-8515, Japan. *email: jsudish@kud.ac.in; shinsan@yamaguchi-u.ac.jp 


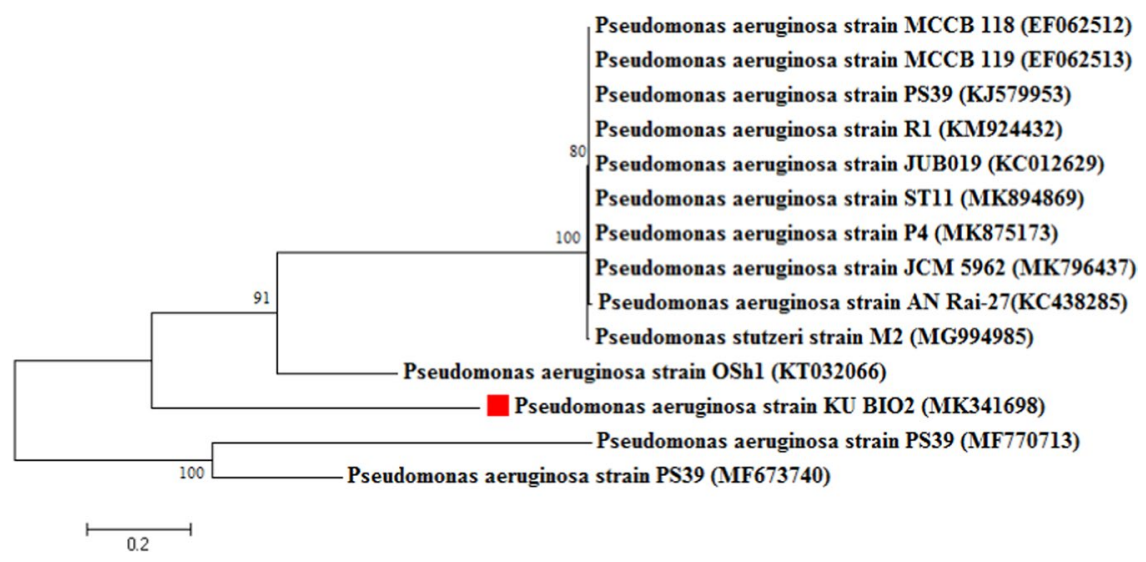

Figure 1. Phylogenetic tree of $16 \mathrm{~S}$ rRNA gene showing resemblance to various isolates of pyocyanin producing bacterium Pseudomonas aeruginosa drawn using MEGA 7.0 software with neighbor joining method (NJ) cluster analysis (numbers inside the branches are bootstrap values).

blue-green phenazine color pigment produced in large quantities ${ }^{12}$. Despite of its antimicrobial and other commercial significant properties, there are reports that the bacterium $P$. aeruginosa are prominent pathogen in nature that cause various health issues especially in hospitalized patients ${ }^{13,14}$.

Pyocyanin is a potent bacterial pigment produced by $P$. aeruginosa with capacity to arrest the electron transport chain of fungi and hence exhibits antifungal activity ${ }^{15}$. Additionally, pyocyanin is a broad spectrum pigment which acts on pathogenic microbes, importantly on wilt disease which is caused by Fusarium oxysporum ${ }^{16}$. In addition to its diverse applications in the agriculture field, pyocyanin is used also in textile industries as a colorant agent for cotton and linen cloths ${ }^{17,18}$. Therefore, the main purposes of this study are (i) to identify and isolate, the pyocyanin producing organism P.aeruginosa from agricultural waste soil (ii) to test productivity of pyocyanin under different nutrients and (iii) characterization of pyocyanin and its evaluation on both the dye and agrochemical properties.

\section{Results}

Isolation and characterization of pyocyanin producing bacteria. A total of seven strains of bacteria designated as KU_BIO1-KU_BIO7 were isolated from the soil. Among the seven strains, KU_BIO2 produced a fluorescent glow and this strain was used for further study. The isolated strain (KU_BIO2) was found to be an aerobic Gram negative bacterium. The fully developed colonies of the strain KU_BIO2 were round in shape with raised elevation. Further, this strain showed positive results for catalase, oxidase and citrate test. The 16S rRNA sequence acquired was 971 bp long, and the isolate was identified as Pseudomonas aeruginosa KU_BIO2 strain and deposited in the National Center for Biotechnology Information (NCBI) GenBank under the accession number MK341698. The nearest relatives were first decided upon based on comparability of their 16S rRNA sequences obtained by a direct blast analysis of the NCBI GenBank. The phylogeny of strain KU_BIO2 was identified by retrieving the Pseudomonas spp. which were classified as able members in pyocyanin production. Based on the phylogeny, the strain KU_BIO2 exhibited 100\% similarity with MK875173 and MK796437 which are potent bacteria for rhizodegradation of used engine oil and biosurfactants production respectively. Overall, the genetic sequence of the isolated strain (KU_BIO2), when blast searched in NCBI, showed high similarity with non-pathogenic bacteria, further none of the pathogenic isolates of $P$. aeruginosa found in the NCBI database showed similarity with this isolate (KU_BIO2) (Fig. 1).

Morphological analysis of the strain by Atomic Force Microscopy (AFM). The cells of P. aeruginosa $\mathrm{KU}-\mathrm{BIO} 2$ strain were scanned between 0 to $2.5 \mu \mathrm{m}$ and it was observed that the single cell was found to be approximately $1.9 \mu \mathrm{m}$ in length and $0.26 \mu \mathrm{m}$ of width as illustrated in Fig. 2.

Production of pyocyanin on different broths. The King's A broth amended with soya as a nutrient yielded maximum pyocyanin followed by the nutrient broth amended by sweet potato. The maximum production in nutrient broth was observed in the sweet potato broth with a concentration $1.702 \mu \mathrm{g} \mathrm{ml}^{-1}$ and the minimum production was observed in the soya bean broth with a concentration $0.1702 \mu \mathrm{g} \mathrm{ml}^{-1}$. The details of pyocyanin production are tabulated in Table 1. The maximum production in King's A broth was observed in the soya bean broth with a concentration $2.560 \mu \mathrm{g} \mathrm{ml}^{-1}$. The minimum production was observed in the watermelon broth with a concentration $0.5106 \mu \mathrm{g} \mathrm{ml}^{-1}$ (Table 2).

Chemical analysis. Confirmative test for the production of pyocyanin using UV spectroscopy. The absorbance spectra of pyocyanin were measured from 200 to $700 \mathrm{~nm}$ wavelength. The absorbance peaks of standard pyocyanin were eluted at 382 and $521 \mathrm{~nm}$ against $0.2 \mathrm{M} \mathrm{HCL}$ as a blank (Fig. 3). Similarly, the absorbance peaks eluted from King's A broth extracts with five different supplements were 214, 277 and $384 \mathrm{~nm}$ for the corn and sweet potato, 212, 277, 384 and $520 \mathrm{~nm}$ for the soya bean and $216 \mathrm{~nm}$ for the watermelon seeds respectively (Fig. 3). Hence by comparing all the peaks in the King's A broth, the soya bean has a higher absorbance peak than 

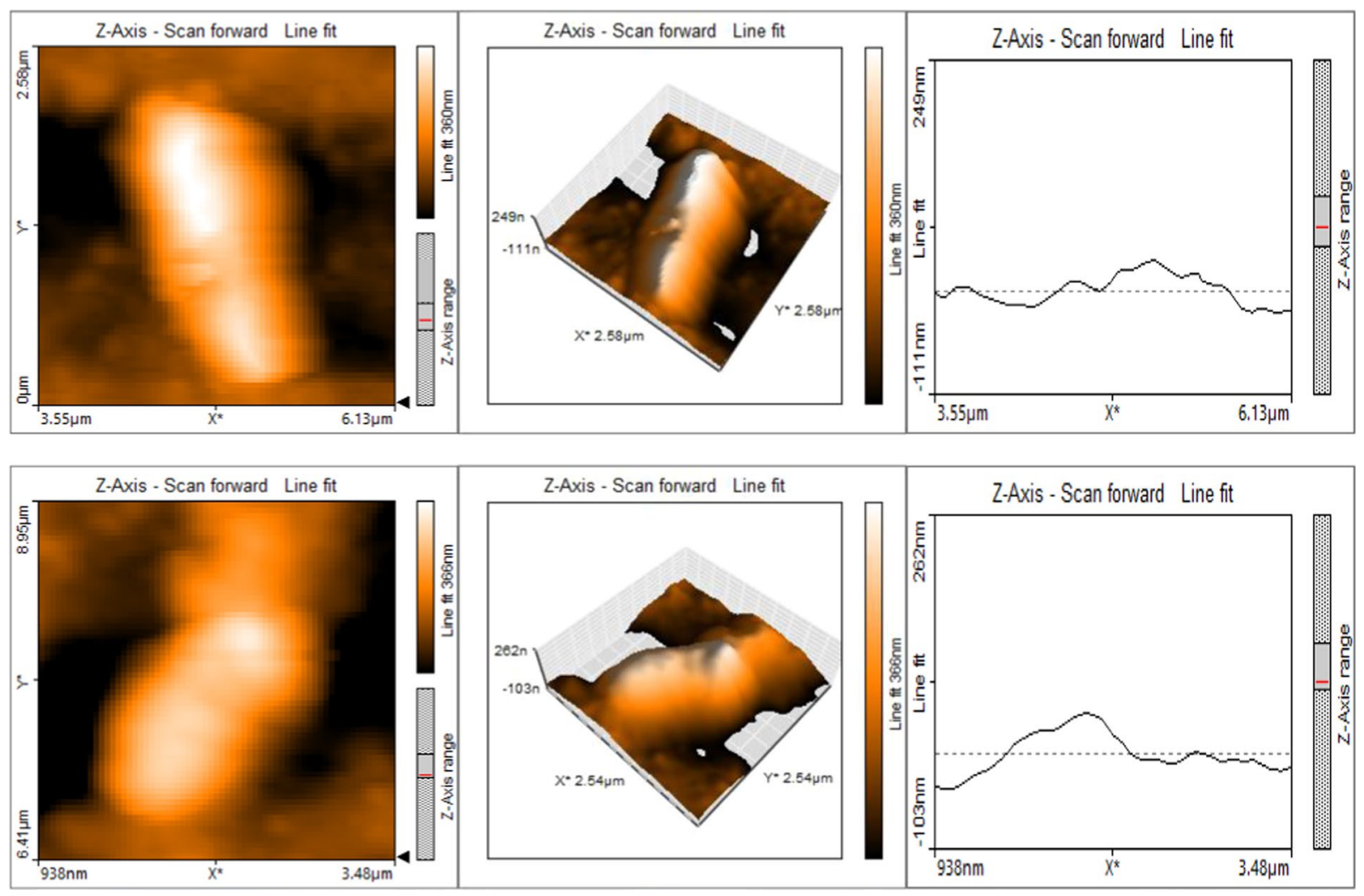

Figure 2. Cell morphology of Pseudomonas aeruginosa strain KU-BIO2 displaying the surface area as analyzed by Atomspheric Fluoresent Microscopy captured at various angles.

\begin{tabular}{|l|l|l|}
\hline Sample name & $\begin{array}{l}\text { Optical density } \\
\text { at 520 } \mathbf{n m}\end{array}$ & Concentration $\left(\boldsymbol{\mu \mathrm { g } \mathrm { ml } ^ { - 1 } )}\right.$ \\
\hline Corn & 0.02 & $0.3414 \pm 0.012^{\mathrm{d}}$ \\
\hline Soya bean & 0.01 & $0.1702 \pm 0.001^{\mathrm{de}}$ \\
\hline Sweet potato & 0.10 & $1.702 \pm 0.031^{\mathrm{a}}$ \\
\hline Watermelon seeds & 0.08 & $1.3616 \pm 0.0011^{\mathrm{b}}$ \\
\hline Groundnut & 0.05 & $0.851 \pm 0.003^{\mathrm{c}}$ \\
\hline
\end{tabular}

Table 1. Production of pyocyanin in nutrient broth amended with different nutrition sources.

\begin{tabular}{|l|l|l|}
\hline Sample name & $\begin{array}{l}\text { Optical density } \\
\text { at 520 } \mathbf{n m}\end{array}$ & Concentration $\left(\boldsymbol{\mu g ~ \mathbf { ~ I } ^ { - 1 } )}\right.$ \\
\hline Corn & 0.11 & $1.877 \pm 0.034^{\mathrm{b}}$ \\
\hline Soya bean & 0.15 & $2.560 \pm 0.021^{\mathrm{a}}$ \\
\hline Sweet potato & 0.10 & $1.702 \pm 0.018^{\mathrm{b}}$ \\
\hline Watermelon seeds & 0.03 & $0.5106 \pm 0.015^{\mathrm{cd}}$ \\
\hline Groundnut & 0.05 & $0.851 \pm 0.009^{\mathrm{c}}$ \\
\hline
\end{tabular}

Table 2. Production of pyocyanin in King's A broth amended with different nutrition sources.

those of the other raw materials used. The maximum production range of pyocyanin in the King's A broth was at $212,277,384$ and $520 \mathrm{~nm}$ in the soya bean and the minimum production was at $214 \mathrm{~nm}$ in the groundnut broth. Similarly, the absorbance peaks seen in the nutrient broths with five different nutrient supplements were 299 and $260 \mathrm{~nm}$ in the corn broth, $256 \mathrm{~nm}$ in the soya bean broth, $222 \mathrm{~nm}$ in the sweet potato broth, $229 \mathrm{~nm}$ in the watermelon seed broth and $235 \mathrm{~nm}$ in the groundnut broth. Hence by comparing all the peaks in the nutrient broths that amended with corn had the highest absorbance peak compared to the others. The maximum production range of pyocyanin in the nutrient broth was at 229 and $260 \mathrm{~nm}$ in the corn broth and the minimum production was at $222 \mathrm{~nm}$ in the sweet potato broth. 

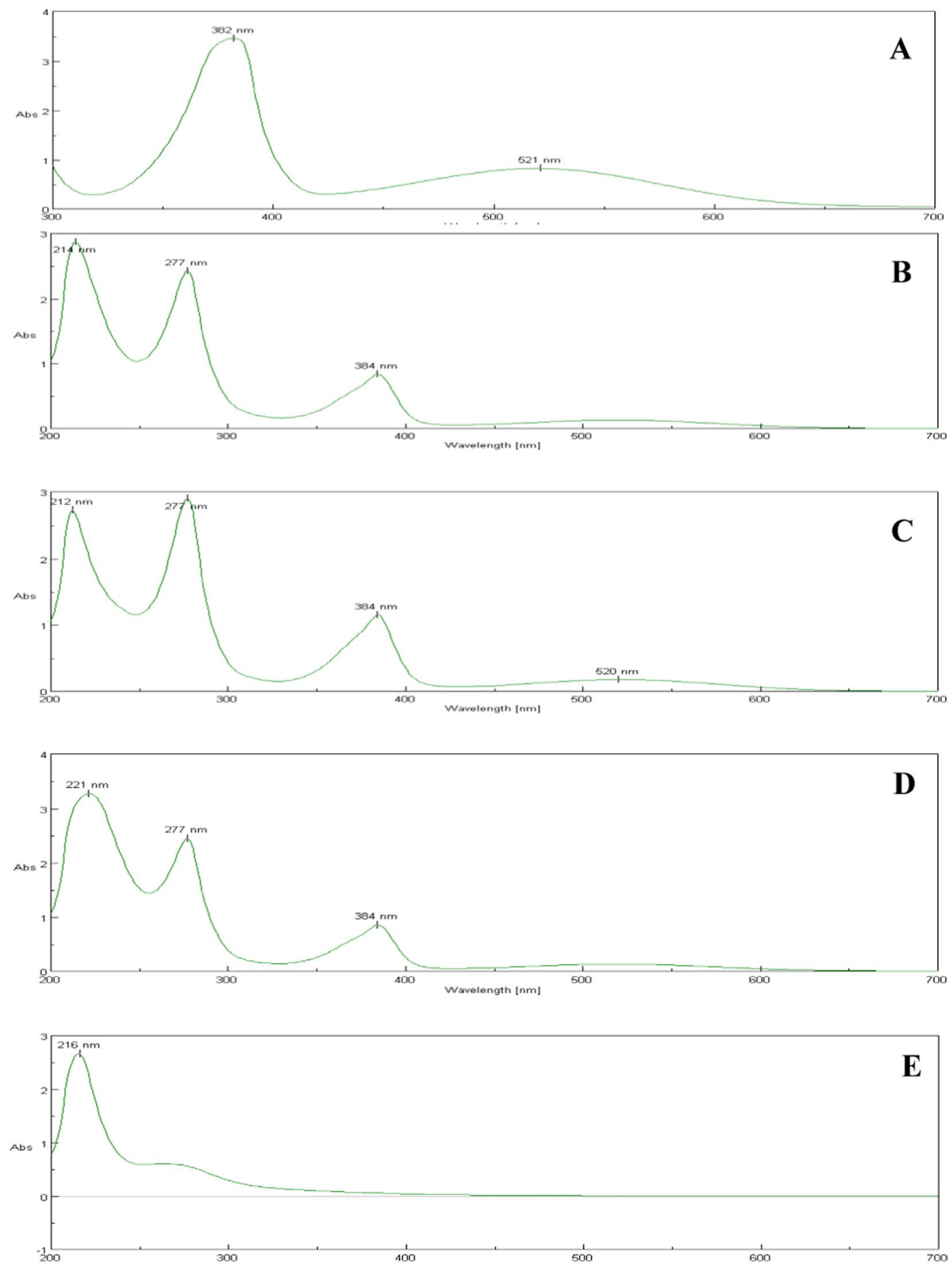

\section{Wavelength}

Figure 3. Spectroscopic absorbance peaks of standard pyocyanin (A) and pyocyanin extracted from the King's A medium amended with corn $(\mathbf{B})$, soya $(\mathbf{C})$, sweet potato $(\mathbf{D})$ and water melon $(\mathbf{E})$.

Similarly, the absorbance peaks seen in the five different nutrient supplement broths were 299 and $260 \mathrm{~nm}$ in the corn, $256 \mathrm{~nm}$ in the soya bean, $222 \mathrm{~nm}$ in the sweet potato, $229 \mathrm{~nm}$ in the watermelon seed and $235 \mathrm{~nm}$ in the groundnut broths respectively (Supplementary Fig. 1).

The standard pyocyanin FTIR data revealed the presence of an Alkenyl C=C stretch at 1604 , a $\mathrm{C}=\mathrm{O}-\mathrm{H}$ stretch Aldehyde at 1405 and a C-C-C stretch, with a medium stretch of 1169. Corresponding to the standards, the test samples exhibited similar molecular functional groups at 1604, 1405 and 1169 (Fig. 4). The standard pyocyanin peak was eluted at 1.05 mins with an $\mathrm{m} / \mathrm{z}$ value of 211.05 and production of 197.04. Similarly, the extracted samples peaks were also eluted at 1.08 and 1.07 for sweet potato and soya bean respectively (Fig. 5). The $1 \mathrm{H}$ NMR 

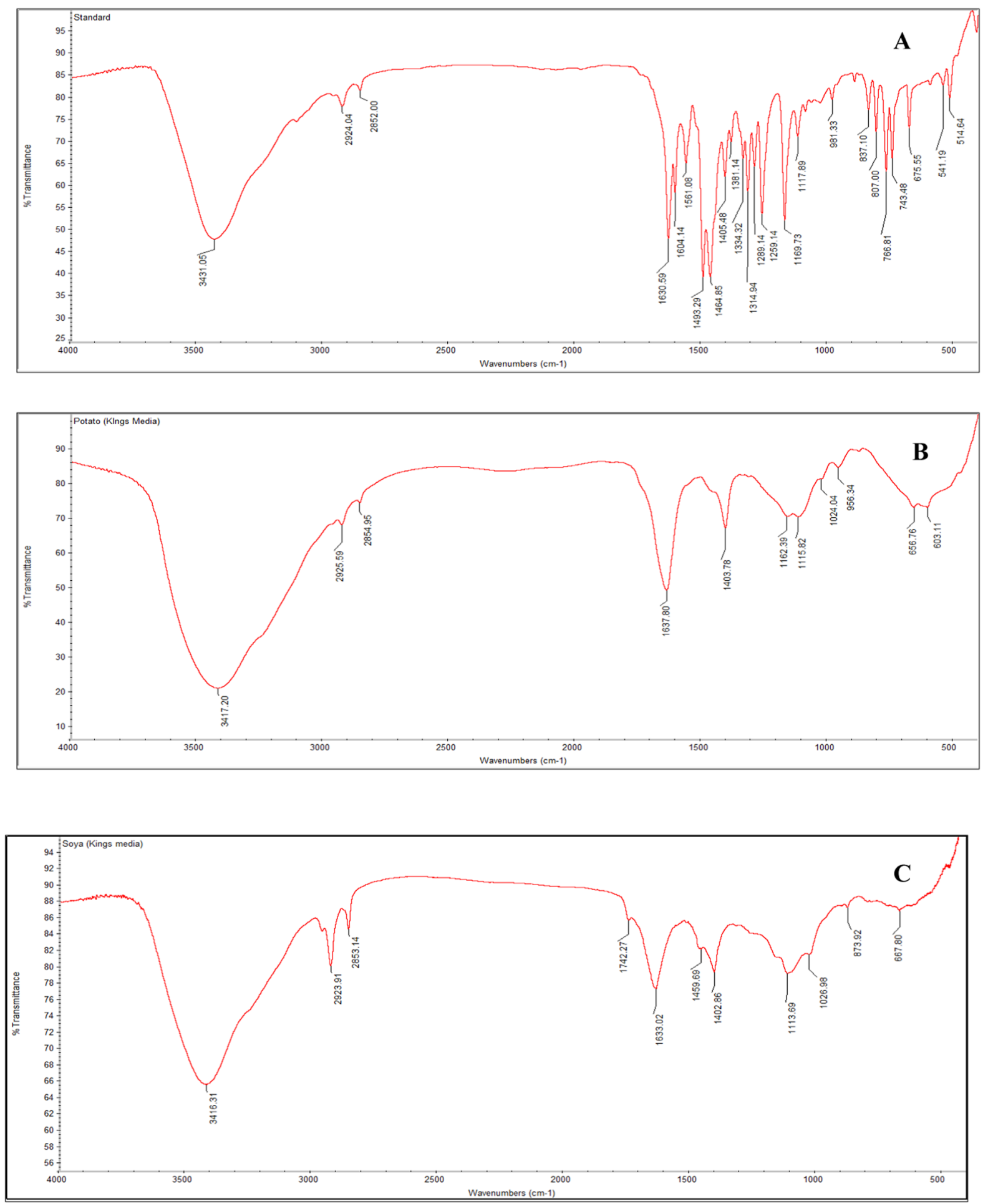

Figure 4. Functional groups spectral annotation by Fourier-Transform Infrared spectroscopy observed for standard pyocyanin $(\mathbf{A})$, Sweet Potato $(\mathbf{B})$ and Soya $(\mathbf{C})$.

spectrum of pyocyanin was recorded with DMSO-d6 and $\mathrm{N}-\mathrm{CH}_{3}$ protons resonated at $3.363 \mathrm{ppm}$ as a singlet, whereas the remaining protons were resonated in the aromatic region from 7.221 to $7.547 \mathrm{ppm}$ as multiplets (Fig. 6).

Antimicrobial properties of pyocyanin. In the antimicrobial susceptibility tests, pyocyanin showed microbial growth inhibiting activity against a tested fungus and a bacterium. Pyocyanin was introduced to the pathogens in different concentrations 1, 5, 10, 50,100, 150 and $200 \mathrm{ppm}$. The bacterial pigment pyocyanin reduced the growth of the fungus Magnaporthe grisea and the bacterium Xanthomonas oryzae and it was noticed that at $200 \mathrm{ppm}$ the growth was completely inhibited. The growth of the fungus was inhibited to the maximum extent at $150 \mathrm{ppm}$ (Fig. 7). 

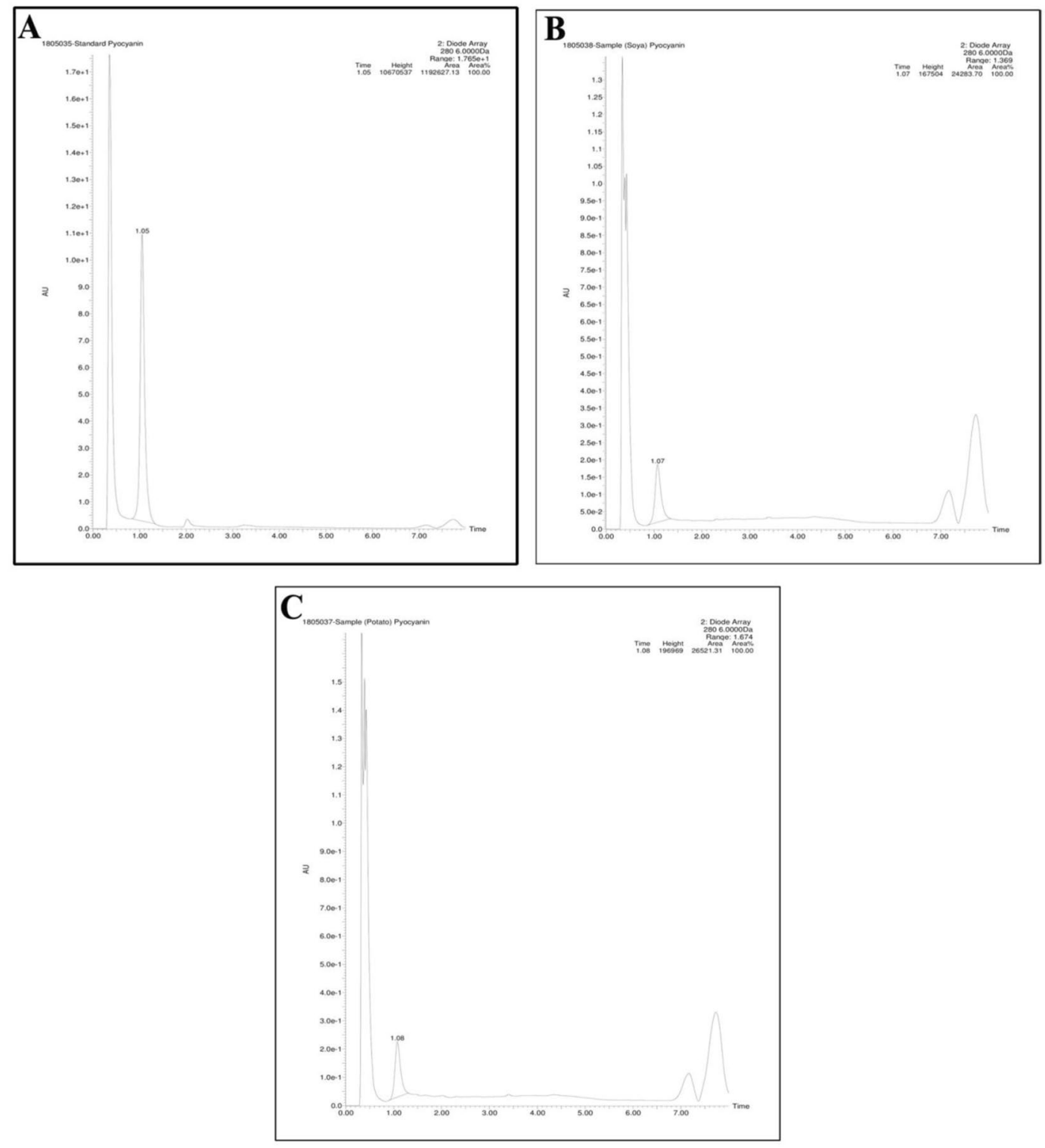

Figure 5. Characterization of pyocyanin by Liquid Chromatography Mass Spectra, Standard pyocyanin peak eluted at $1.05 \mathrm{mins}$ (A), $1.07 \mathrm{mins}$ for Soya sample (B) and and1.07 mins for Sweet potato (C).

Pyocyanin as a textile dye. The extracted pyocyanin showed the property of a textile dye and the results obtained using cotton cloth are shown in the Fig. 8 . The cotton cloth treated with pyocyanin pigment extract showed the change in colour from white to pink. After dye application and 3-5 times washing with soap, the color change remained.

\section{Discussion}

Pseudomonas aeruginosa is an opportunistic bacterium with commercial value and it is well known for its ability to secrete phenazine compounds ${ }^{18}$. It is responsible for broad spectrum of activities, such as dye decoloration $^{19}$, food colorants ${ }^{20}$, antibacterial ${ }^{20}$, antifungal ${ }^{21}$, nematocidal ${ }^{21}$ and pesticide degradation ${ }^{22}$. Moreover, $P$. aeruginosa has also been documented for its efficacy in plant growth promotion and is a promisive biocontrol candidate ${ }^{23}$. This microorganism exhibits a versatile biological activity which can be utilized for solving many agricultural $^{20,21,23}$ and environmental issues ${ }^{24}$.

In this study, seven bacterial strains were isolated from agricultural waste soil and screened for pyocyanin production. Among the seven bacteria, isolate KU-BIO2 was found to be promising in pyocyanin production, and based on the 16s rRNA analysis it was identified as P. aeruginosa (Fig. 1). The sequence readings of the isolate KU-BI02 showed high similarity with various other isolates of $P$. aeruginosa that had been previously reported for beneficial application such as bioremediation or oil degradation and biosurfactant production (Fig. 1). In this study, we also noticed a enhanced pyocyanin production by this isolate KU-BIO2 that was achieved by amendment of the nutrients in the growth medium, and maximum production was obtained in King's A broth 


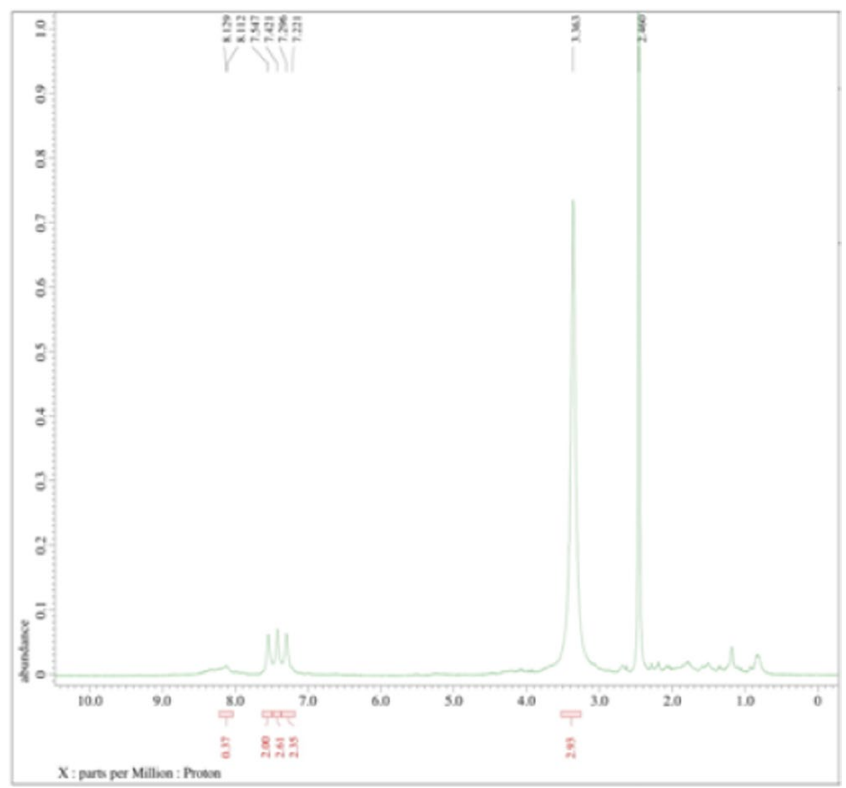

Figure 6. Structural elucidation of pyocyanin by Nuclear Magnetic Resonance Spectrum resonating at 3.363 ppm as a singlet.
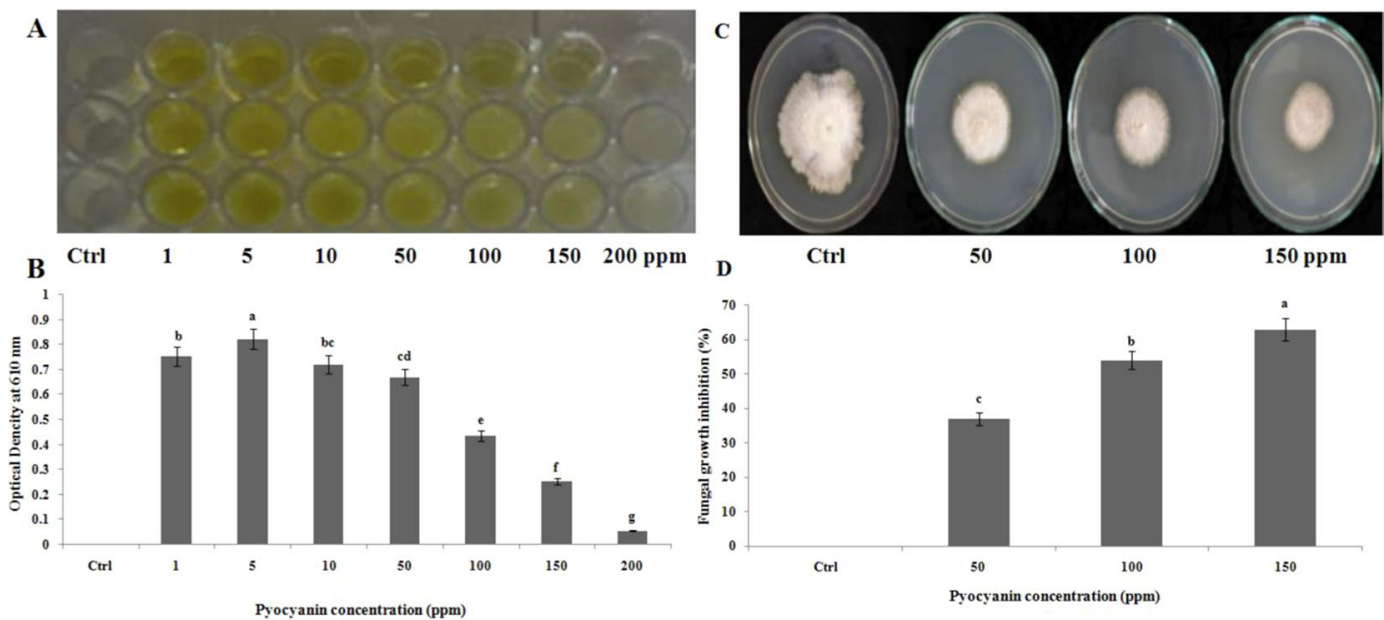

Figure 7. Agrochemical properties of extracted pyocyanin. (A) and (C) photographs exhibiting growth inhibiting action at $200 \mathrm{ppm}$ against Xanthomonas oryzae (A) and at $150 \mathrm{ppm}$ against Magnaporthe grisea (C), respectively. Images (B,D) showing the quantification of $X$. oryzae load measured at $610 \mathrm{~nm}$ and (D) The diameter of zone of inhibition in M. oryzae growth. Values are the mean of four independent replicates \pm standard errors $(\mathrm{n}=4)$. Significance of the data are measured according to Tukey's HSD test.

A

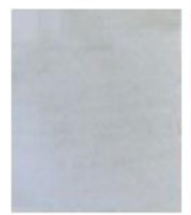

B

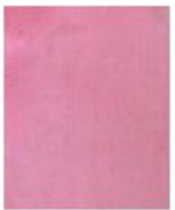

C

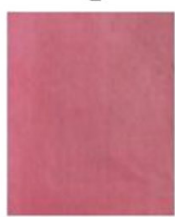

D

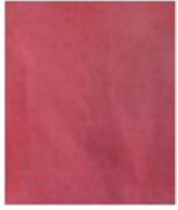

Figure 8. Textile dye application of extracted pyocyanin pigment on white cotton cloth. Cloth without the application of pyocyanin (A), cloth washed after the six hours of pyocyanin application (B), cloth washed with soap after $12 \mathrm{~h}$ of pyocyanin application $(\mathrm{C})$, cloth washed with water after $12 \mathrm{~h}$ of treatment and cloth showing higher dye accumulation after $24 \mathrm{~h}$ of pyocyanin application (D). 
(Table 1) when compared to nutrient broth (Table 2). It was observed that the production of pyocyanian is nutrient dependent, the amendement of natural nutrients such as carbohydrate, fat, minerals and proteins in the form of soya bean in King's A growth medium carrying peptone, magnesium chloride and glycerol as a major chemical nutrients influence the production of pyocyanin, these combined natural and chemical nutrients in King's A medium play a vital role by increasing the bacterial density and would produce maximal amounts of pyocyanin pigment. While, nutrient broth is provided with low energy sources. Therefore, we reason that the pigment is contributed in association and or dependent with supplemented natural nutrients. Similarly, Devnath et al. ${ }^{25}$ observed the maximum pyocyanin pigmentation from the growth medium amended with peptone, magnesium chloride and glycerol, and increase pigment formation was observed in combination with magnesium chloride and inorganic ions. In the past, various researchers reported the usage of traditional low cost carbon sources for Pseudomonas spp. growth and higher pyocyanin production. For instance, molasses as a rich carbon act as a growth promoting substrate for Pseudomonas spp. and pyocyanin production ${ }^{26}$. Similar investigation was performed by E-Fouly et al..$^{27}$ in which pyocyanin production from P.aeuroginosa was carried out using glycerol supplemented nutrient broth (GSNB), Mineral Medium and King's A broth and it was concluded that the production of pyocyanin was enhanced by using raw materials as nutrient sources. These results support our conclusion that the production of pyocyanin is nutrient dependent and the microbes have an advantage in synthesis of important pigments by the use of a variety of raw nutrients under varying cultivation processes ${ }^{27,28}$. Hence, based on our results it can be considered as a low cost chemical and natural nutrients are essential for the microbial growth and metabolism underlying the glycolysis pathway, where microbes used food for the energy to run cellular processes, thereby bestow enhanced production of pyocyanin.

On the contrary, pyocyanin is synthesized commercially using chemical reagents such as phenazine methasulfate, nitrogen, chloroform, hexane, methanol, millipore water, hydrochloric acid Tris-HCL and sodium hydroxide ${ }^{29}$. Such chemical synthesis is expensive and time consuming. To overcome this issue, in the present investigation the pyocyanin was naturally produced from the P.aeuroginosa strain KU-BIO2 within three days. Likewise, E-Fouly et al. ${ }^{27}$ reported maximum pyocyanin production from P.aeuroginosa after the fourth day. Although synthesis of natural pigment is time consuming, pyocyanin has been successfully extracted using a microbial source within a short period using simple raw nutrients. Moreover, the media plays a crucial role in the microbial growth and enhanced production of pyocyanin, and a number of synthetic media are strongly suggested for pyocyanin production under low proliferation of $P$. aeruginos $a^{21}$. Interestingly, the $P$. aeruginosa oxyR mutant is unable to grow in LB medium unless high quantities of cells are inoculated. Conversely, the growth in King's A media is found to be optimum with induced pyocyanin and rhamnolipid production ${ }^{30}$. In the present study, evidence is provided for the improved growth and cell proliferation of P. aeruginosa in King's A medium when compared to the Nutrient broth. Being a versatile agent, $P$. aeruginosais able to utilize various types of carbon sources for the production of rhamnolipids ${ }^{31}$.

The absorbance peak of standard pyocyanin was eluted at 382 and $521 \mathrm{~nm}$ against $0.2 \mathrm{M} \mathrm{HCL}$ as a blank (Fig. 3A). Likewise, the pyocyanin extracted from King's A media supplemented with corn, soya bean or sweet potato showed elution at $384 \mathrm{~nm}$ (Fig. 3B-D) and confirms pyocyanin presence in the media. Other pyocyanin characteristic peaks under UV-Vis spectrophotometer examination are in agreement with Ohfuji et al. ${ }^{32}$. Similarly, Kerr et al. ${ }^{15}$ reported the use of the UV-Visible spectrophotometer for detection of pyocyanin pigment successfully extracted from different growth media. The isolated pyocyanin was characterized by LCMS and the molecular ion of pyocyanin was found at $211 \mathrm{~m} / \mathrm{z}$, this data outcome being supported by E-Fouly et al. ${ }^{27}$. Furthermore, the $1 \mathrm{H}$ NMR spectrum of pyocyanin was recorded by DMSO-d6 and $\mathrm{N}-\mathrm{CH}_{3}$ protons which were resonated at $3.363 \mathrm{ppm}$ as a singlet, and others were resonated in the aromatic region from 7.221-7.547 ppm (Fig. 6), and this result is in accordance with the earlier report ${ }^{33}$.

In the present study, pyocyanin was found to be effective against Magnaporthe grisea and Xanthomonas oryzae at 150 and 200 ppm, respectively (Fig. 7). Abdul-Hussein \& Atia ${ }^{34}$ reported that the growth of Escherichia coli and of Aspergillus fumigatus were inhibited in the range between 10 to $100 \mu \mathrm{g} \mathrm{ml}^{-1}$, while the growth of yeast Cryptococcus neoformans was equally inhibited by pyocyanin. In another study, E. coli, Bacillus sp., and Aspergillus niger strains were found to be sensitive to the phenazin pigment pyocyanin at 0.005 to $50 \mu \mathrm{g}$ as analyzed by the tube dilution and agar well diffusion methods ${ }^{35}$. The antagonistic activity of pyocyanin was studied at low concentration of $100 \mu \mathrm{L}$ against Macrophomina phaseolina plant pathogenic fungus that is responsible for stem rot, seedling blight and root rot. These authors noticed that the pyocyanin was exhibited as a tremendous growth inhibiting agent against M. phaseolina and could suppress the associated diseases very effectively at low concentration, and the inhibitory action of $100 \mu \mathrm{l}$ of purified pyocyanin against various phytopathogens and saprophytic molds was also reported ${ }^{36}$. The quorum sensing $P$. aeruginosa producing pyocyanin is correlated with siderospores activity that possesses antibacterial property ${ }^{37}$. In another independent research, it was observed that the phenazin pigment $50 \mu \mathrm{g}$ produced by $P$. aeruginosa inhibit the growth of Candida albicans and Aspergillus fumigatus fungal growth ${ }^{38}$. The broad spectrum of antagonistic and biocontrol properties of pyocyanin isolated from $P$. aeruginosa is well documented ${ }^{39}$. It is also reported that pyocyanin isolated from oil degrading $P$. aeruginosa strain exhibit remarkable antimicrobial properties ${ }^{40}$.

Many of the microbial mediated compounds not only show antimicrobial activities but also possess ecofriendly coloring agents that can be used in food processing, textile and cosmetic industries with high demand ${ }^{41-43}$. In the past there have been well documented reports about the production of bio-pigments, namely flavins, quinines, carotenoids and melanins, from various microbial origins ${ }^{42,44}$. However, in the Indian scenario, very limited research results on the utilization of microoranisms for the production of pyocyanincolor pigments are available. In this context and in view of an eco-friendly industrial approach, synthetic dyes are becoming expensive and causing many harmful effects on the environment and hence nowdays research on natural and biological dyes is gaining much attention ${ }^{45}$. Microbial pigments are regularly characterized as industrial dyes and coloring agents in preparation of foods and paints ${ }^{46,47}$. Additionaly, some microbial strains are used as a textile colorants. For 
example Flavobacterium sp. ${ }^{48}$, P. aeruginosa and Serratia marcescens ${ }^{49}$ produce distinct colors. Likewise, in the current study the $P$. aeruginosa KU-BIO2 strain was found to produce pyocyanin pigment effects on white cotton cloth producing a pink color (Fig. 8) which has a significant role to play in textile industries. Though, pyocyanin is widely used in industrial and agricultural applications, there are adverse effects of pyocyanin on human health such as cardiovascular, respiratory and nervous system $s^{50}$. In another study, pyocyanin induces the cytotoxicity in human embryonic lung epithelial cell line ${ }^{51}$ and mammalian cells ${ }^{52}$.

The findings from these studies clearly illustrate that the pyocyanin can act as a potential agrochemical properties which can reduce the use of toxic fungicides. Further, evidence is provided about the use of pyocyanin pigment in textile industries such as it being a natural colorant for materials in the manufacture of fabrics and carpets, as well as coloring paper, and the possibility exists with using in textile and dye making industries.

\section{Methods}

Chemicals and soil samples. Standard pyocyanin with a purity of $98 \%$ was procured from the Cayman Chemical Company, USA. The chloroform and hydrochloric acid used were of high analytical grade, and for the isolation of Pseudomonas aeruginosa, Citrimide broth (CB), Nutrient agar (NA) and King's A medium (Himedia, Mumbai, India) were utilized. The soil samples were collected from where agricultural waste was dumped in Dharwad. Karnataka, India.

Isolation of Pseudomonas species. One gram of finely sieved soil sample was serially diluted up to $10^{-7}$ using sterile saline solution, and $100 \mu \mathrm{l}$ of $10^{-5}$ and $10^{-6}$ dilutions were aseptically inoculated to tubes containing $10 \mathrm{ml} \mathrm{CB}$ and incubated at $35^{\circ} \mathrm{C}$ for $24 \mathrm{hrs}$. After the incubation, an aliquot of $100 \mu \mathrm{l}$ was spread plated on the NA and incubated at $35^{\circ} \mathrm{C}$ for $24 \mathrm{hrs}$. Further, the fully grown colonies were purified by using the quadrant streak method and stored at $4^{\circ} \mathrm{C}$ until needed for further use.

Characterization of Pseudomonas species. All the isolates were screened initially by their colony morphology and gram nature, and biochemically by testing the positive interaction with oxidase and catalase, gelatin liquefaction and citrate utilization tests. Additionally, the ability of the isolates to grow at high temperatures (40 to $45^{\circ} \mathrm{C}$ ) was also investigated. Further, Pseudomonas spp. was confirmed by the pigment coloration (fluorescent glow) on the NA. The cells of Pseudomonas spp. grown in CB were fixed on a clean glass slide and were scanned at different resolution ranges using Flex-Bio Atomic Force Microscope (AFM) (Nanosurf) with C3000 controller for cell morphology analysis. Later, the isolate was subjected to molecular characterization with 16S rRNA universal primer in a thermal cycler ${ }^{2}$.

Nutrient sources for the enhanced production of the pyocyanin pigment. Five nutrient sources (NS) were selected for the enhanced production of pyocyanin. NSs like sweet corn, sweet potato, watermelon seeds, peanuts and soya seeds were chosen. Sweet corn was washed with distilled water, finely ground and stored in the refrigerator until used, the sweet potato was boiled in water and the boiled water filtered and used. Watermelon seeds, soya seeds and peanuts were washed, dried and finely ground using mortar and pestle and stored in a polythene bag until further use.

Enhanced production of pyacyanin pigment. The enhanced production of pyocyanin was done using Nutrient Broth (NB) and King's A medium. A $100 \mu \mathrm{l}$ of liquid culture consisting of cell density $3 \times 10^{6} \mathrm{cfu} \mathrm{ml}^{-1}$ was inoculated to $100 \mathrm{ml} \mathrm{NB}$ and King's A medium supplemented with one percent of NS and incubated at $35^{\circ} \mathrm{C}$ in a shaker incubator $(160 \mathrm{rpm})$ up to $\log$ phase. Bacteria grown without NS were treated as control and the growth of the strain was monitored during the study.

Extraction of pyocyanin by Pseudomonas species. At the log phase of bacterial growth, the broth culture was withdrawn from each of the flasks and subjected to centrifugation at $12,000 \times \mathrm{g}$ for $20 \mathrm{~min}$ at $4{ }^{\circ} \mathrm{C}$. The supernatant was then collected and thoroughly mixed with $4.5 \mathrm{ml}$ of chloroform and vortexed for 20 secs for colour change, and the biomass which was settled at the bottom was dried at $75^{\circ} \mathrm{C}$ and the obtained dried biomass was considered weight per volume. Then, (chloroform sinks to the bottom of the tube, make sure that the supernatant moves with chloroform when vortex, the color of chloroform changes from green to blue). Samples were centrifuged at $10,000 \times \mathrm{g}$ for $10 \mathrm{mins}$ at $4^{\circ} \mathrm{C}$ and then three $\mathrm{ml}$ of the blue layered solution settled at the bottom of the tube were transferred to another new set of tubes and $1.5 \mathrm{ml}$ of $0.2 \mathrm{M} \mathrm{HCl}$ was introduced to each tube, properly mixed, and further subjected to centrifugation for five mins at $10,000 \times \mathrm{g}$, the resultant suspension containing pigment was stored in $4^{\circ} \mathrm{C}$ until further use. The supernatant obtained was utilized to measure the density of extracted crude pyocyanin at different wavelengths in a spectrophotometer (Hitachi U2900). The intensity of pyocyanin concentration $\left(\mu \mathrm{g} \mathrm{ml}^{-1}\right)$ was calculated by multiplying the optical density (OD) value obtained at $520 \mathrm{~nm}$.

Purification of pyocyanin pigment. The crude pyocyanin pigment was purified by the method described in E-Fouly et al. ${ }^{27}$. Briefly, the crude pigment was suspended in chloroform and absorbed on silica gel. Further, the absorbed pigment samples were loaded onto the column which was equilibrated by methanol and chloroform and later the elution of pure pigment was done using a combination methanol and chloroform.

Chemical analysis. Confirmatory test for the production of pyocyanin by UV spectroscopy. The obtained pigment was re-dissolved in five $\mathrm{ml}$ of chloroform and utilized to measure the density of the extracted pyocyanin at different wavelengths $(300-700 \mathrm{~nm})$ using a spectrophotometer (Hitachi U2900). The intensity of pyocyanin concentration $\left(\mu \mathrm{g} \mathrm{ml}^{-1}\right)$ was calculated by multiplying the optical density (OD) value obtained at $520 \mathrm{~nm}$. 
Identification of functional groups by Fourier-Transform Infrared spectroscopy (FTIR). The extracted pyocyanin samples from different sources was encapsulated in $200 \mathrm{mg}$ of $\mathrm{KBr}$ (Sigma-Aldrich) in order to prepare translucent sample disks homogenized with KBr. The spectra were measured using a Nicolet FT-IR 6700 (Thermo Fisher Scientific) in the IR region, a single beam splitter, and a DTGS-KBr detector at spectrometer range 4000 to $400 \mathrm{~cm}^{-1}$.

Characterization of pyocyanin by Liquid Chromatography-Mass Spectrometry (LCMS). An aliquot of standard and extracted pyocyanin was used for the LCMS analysis. Ten $\mu \mathrm{l}$ of analyte was subjected to LC (Aquity, Waters) equipped with BEH C18 of $1.7 \mu \mathrm{m}$ of a $1.0 \times 50 \mathrm{~mm}$ column and followed by mass spectrometry, the mass range being ionized by the Synapt G2 Waters. An analyte prepared with $0.1 \%$ formic acid in water in combination with acetonitrile was subjected to LC at controlled room temperature and column temperature of $50^{\circ} \mathrm{C}$ in gradient mode for 8 mins reverse phase.

Elucidation of pyocyanin structure by NMR. The lyophilized sample of pyocyanin was checked for its solubility and it was clearly soluble in DMSO solvent. Ten $\mathrm{mg}$ of the sample was dissolved in the NMR tube containing DMSO solvent, the DMSO solvent was filled till it reached about $4-5 \mathrm{~cm}$ of the tube. The tube was gently shaken for all the material to dissolve. Then the NMR tube was inserted into a spinner and was taken out from the spinner after applying a magnetic field and was placed in the NMR spectrometer.

Antimicrobial assay of pyocyanin. The antifungal assay of pyocyanin was examined by the method of Jogaiath et al. ${ }^{4}$ and Joshi et al. ${ }^{53}$. Briefly, rice blast caused by the Magnaporthe grisea and bacterial blight of rice, Xanthomonas oryzae, were tested against the pyocyanin on Potato Dextrose Agar (PDA) and Nutrient Broth medium (NB) respectively. PDA petri dishes supplemented with pyocyanin at $2.560 \mu \mathrm{g} \mathrm{ml}^{-1}$ concentration were inoculated with Magnaporthe grisea and incubated for five days at $25 \pm 2{ }^{\circ} \mathrm{C}$. PDA petri plates and 96 -well microtiter plates without pyocyanin served as the control. The minimal inhibitory concentration (MIC) value of Xanthomonas oryzae was analysed for pyocyanin and this was determined by a micro dilution method with the initial cell load of $5 \times 10^{5} \mathrm{CFUml}^{-1}$ and measured using spectrophotometer at $610 \mathrm{~nm}$.

Application of pyocyanin as a textile colorant. The scope for probable application of the bacterial pigment was evaluated on textile white cotton material commercially available in the market. The bacterial pigment was applied to the cloth material which was then washed with soap solution, rinsed with tap water to remove the unfixed dye substances present at the surface level, dried at room temperature and ironed ${ }^{17}$.

Ethical approval. This article does not contain any studies related to human participants or animals.

Received: 26 June 2019; Accepted: 19 November 2019;

Published online: 31 January 2020

\section{References}

1. Satapute, P. et al. Isolation and characterization of nitrogen fixing Bacillus subtilis strain as-4 from agricultural soil. Int. J. Rec. Sci. Res. 3, 762-765 (2012).

2. Jogaiah, S. et al. Isolation and evaluation of proteolytic actinomycete isolates as novel inducers of pearl millet downy mildew disease protection. Scientific Reports 6, 30789 (2016).

3. Satapute, P., Paidi, M. K., Kurjogi, M. \& Jogaiah, S. Physiological adaptation and spectral annotation of Arsenic and Cadmium heavy metal-resistant and susceptible strain Pseudomonas taiwanensis. Environmental Pollution 251, 555-563 (2019).

4. Jogaiah, S., Kurjogi, M., Abdelrahman, M., Nagabhushana, H. D. \& Tran, L.-S. P. Ganoderma applanatum-mediated green synthesis of silver nanoparticles: Structural characterization, and in vitro and in vivo biomedical and agrochemical properties. Arabian Journal of Chemistry, 12, 1108-1120 (2019).

5. Md. Hussain, S. et al. M. Current approaches toward production of secondary plant metabolites. J. Pharm. Bioallied. Sci. 4, 10-20 (2012).

6. Pickens, L., Tang, Y. \& Chooi, Y.-H. Metabolic Engineering for the Production of Natural Products. Annu. Rev. Chem. Biomol. Eng. 2, 211-236 (2011).

7. Guerriero, G. et al. Production of Plant Secondary Metabolites: Examples, Tips and Suggestions for Biotechnologists. Genes (Basel) 9, 309 (2018)

8. Venil, C. K., Zakaria, Z. A. \& Ahmed, W. A. Bacterial pigments and their applications. Process Biochemistry 48, 1065-1079 (2013).

9. Rao, M. P. N., Xiao, M. \& Li, W.-J. Fungal and Bacterial Pigments: Secondary Metabolites with Wide Applications. Front Microbiol. 8, $1113(2017)$.

10. Usman, H. M., Abdulkadir, N., Gani, M. \& Maiturare, M. M. Bacterial pigments and its significance. MOJ Bioequiv. Availab. 4, 285-288 (2017).

11. Krieg, N. R. et al Bergey's Manual of Systematic Bacteriology, 2nd ed.; Springer-Verlag: New York, USA (2010).

12. Blankenfeldt, W. \& Parsons, J. F. The structural biology of phenazine biosynthesis. Current Opinion in Structural Biology 29, 26-33 (2014).

13. Gellatly, S. L. \& Hancock, R. E. W. Pseudomonas aeruginosa: new insights into pathogenesis and host defenses. Pathogens and Disease 67, 159-173 (2013).

14. Arancibia, F. et al. Community-acquired pneumonia due to gram-negative bacteria and Pseudomonas aeruginosa: incidence, risk, and prognosis. Arch. Intern. Med. 162, 1849-1858 (2002).

15. Kerr, J. R. et al. Pseudomonas aeruginosa pyocyanin and 1-hydroxyphenazine inhibit fungal growth. Journal of Clinical Pathology 52, 385-387 (1999)

16. Mahmoud, S. Y., El-Sayed, H. Z., Farrag, E. S., Kalafalla, R. S. \& Mohamed, A. A. Antifungal activity of pyocyanin produced by Pseudomonas aeruginosa against Fusarium oxysporum Schlech a root-rot phytopathogenic fungi. International. Journal of PharmTech Research 9, 43-50 (2016).

17. Jissa, K. G., Soorej, M. B., Beena, P. S. \& Chandrasekaran, M. Marine bacteria as source of pigment for application as dye in textile industry. Proc. Internatl. Conf. Biodiv. Conserv. and Manag. 4, 743-750 (2008). 
18. Alzahrani, S. H. \& Alqahtani, F. S. Pyocyanin Pigment Extracted from Pseudomonas aeruginosa Isolate as Antimicrobial Agent and Textile Colorant. Int. J. of Scientific Research 5, 467-470 (2017).

19. Bhatt, N., Patel, K. C., Keharia, H. \& Madamwar, D. Decolorization of diazo-dye Reactive Blue 172 by Pseudomonas aeruginosa NBAR12. J. Basic Microbiol. 45, 407-18 (2005).

20. Saha, S., Thavasi, R. \& Jayalakshmi, S. Phenazine Pigments from Pseudomonas aeruginosa and Their Application as Antibacterial Agent and Food Colourants. Research Journal of microbiology 3, 122-128 (2008).

21. Kavitha, K. et al. Broad spectrum action of phenazine against active and dormant structures of fungal pathogens and root knot nematode. Archives of Phytopathology and Plant Protection 38, 69-76 (2005).

22. Satapute, P. \& Kaliwal, B. Biodegradation of the fungicide propiconazole by Pseudomonas aeruginosa PS-4 strain isolated from a paddy soil. Ann. Microbiol. 66, 1355-1365 (2016).

23. Anupama, N. B., Jogaiah, S., Ito, S.-i, Amruthesh, K. N. \& Tran, L.-S. P. Improvement of growth, fruit weight and early blight disease protection of tomato plants by rhizosphere bacteria is correlated with their beneficial traits and induced biosynthesis of antioxidant peroxidase and polyphenol oxidase. Plant Science 231, 62-73 (2015).

24. Satapute, P., Kamble, M. V., Adhikari, S. S. \& Jogaiah, S. Influence of triazole pesticides on tillage soil microbial populations and metabolic changes. Sci. Total Environ. 651, 2334-2344 (2019).

25. Devnath, P., Uddin, M., Ahamed, K., Md. Hossain, F. \& Manchur, T. M. A. Extraction, Purification and Characterization of pyocyanin produced by Pseudomonas aeruginosa and evaluation for its antimicrobial activity. Int. Res. J. Biological Sci. 6, 1-9 (2017).

26. Onbasli, D. \& Aslim, A. Determination of antimicrobial activity and production of some metabolites by Pseudomonas aeruginosa B1 and B2 in sugar beet molasses. African Journal of Biotechnology 7, 4614-4619 (2008).

27. E-Fouly, M. Z., Sharaf, A. M., Shahin, A. A. M., El-Bialy, H. A. \& Omara, A. M. A. Biosynthesis of pyocyanin pigment by Pseudomonas aeruginosa. Journal of Radiation Research and Applied Sciences 8, 36-48 (2015).

28. Singh, O. V. \& Kumar, R. Biotechnological production of gluconic acid: future implications. Applied Microbiology and Biotechnology 75, 713-722 (2007).

29. Cheluvappa, R., Shimmon, R., Dawson, M., Hilmer, S. N. \& Le Couteur, D. G. Reactions of Pseudomonas aeruginosa pyocyanin with reduced glutathione. Acta Biochimica Polonica 55, 571-580 (2008).

30. Vinckx, T., Wei, Q., Matthijs, S. \& Cornelis, P. The Pseudomonas aeruginosa oxidative stress regulator OxyR influences production of pyocyanin and rhamnolipids: protective role of pyocyanin. Microbiology 156, 678-686 (2010).

31. Sidal, U. \& Yilmaz, E. S. Production of rhamnolipid (A Biosurfactant) using free and immobilized cells of Pseudomonas sp. KafkasUniversitesi Veteriner Fakultesi Dergisi. 18, 285-289 (2012).

32. Ohfuji, K. et al. Construction of a glucose sensor based on a screen-printed electrode and a novel mediator pyocyanin from Pseudomonas aeruginosa. Biosensors and Bioelectronics 19, 1237-1244 (2004).

33. Priyaja, P. et al. Antagonistic effect of Pseudomonas aeruginosa isolates from various ecological niches on Vibriospecies pathogenic to crustaceans. Journal of Coastal Life Medicine. 2, 76-84 (2014).

34. Abdul-Hussein, Z. R. \& Atia, S. S. Antimicrobial Effect of Pyocyanin Extracted from Pseudomonas aeruginosa. European Journal of Experimental Biology 6, 1-4 (2016).

35. Özyürek, B. S., Gür, S. D. \& Bilkay, I. S. Investigation of Antimicrobial Activity of Pyocyanin Produced by Pseudomonas aeruginosa Strains Isolated from Different Clinical Specimens. Hacettepe J. Biol. \& Chem. 44, 1-6 (2016).

36. Khare, E. \& Arora, N. K. Dual activity of pyocyanin from Pseudomonas aeruginosa-antibiotic against phytopathogen and signal molecule for biofilm development by rhizobia. Can. J. Microbiol. 57, 708-713 (2011).

37. Castañeda-Tamez, P. et al. Pyocyanin Restricts Social Cheating in Pseudomonas aeruginosa. Front. Microbiol. 9, 1348, https://doi. org/10.3389/fmicb.2018.01348 (2018).

38. Price-Whelan, A., Dietrich, L. E. P. \& Newman, D. K. Rethinking 'secondary' metabolism: Physiological roles for phenazine antibiotics. Nat. Chem. Biol. 2, 71-78 (2006).

39. Jayaseelan, S., Ramaswamy, D. \& Dharmaraj, S. Pyocyanin: production, applications, challenges and new insights. World J. Microbiol. Biotechnol. 30, 1159-1168 (2014).

40. Norman, R. S., Moellar, P., McDonald, T. J. \& Morris, P. J. Effect of pyocyanin on a crude-oil-degrading microbial community. Appl. Environ. Microbial. 70, 4004-4011 (2004).

41. Venil, C. K. Lakshmana, P. An insightful overview on microbial pigment, prodigiosin. Elect. J. Biol. 5, 49-61 (2009).

42. Tuli, H. S., Chaudhary, P., Beniwal, V. \& Sharma, A. K. Microbial pigments as natural color sources: current trends and future prospectives. J. Food Sci. Tech. 52, 4669-4678 (2015).

43. Jisss, K. G., Jacob, A., Kurian, P., Elyas, K. K. \& Chandrasekaran, M. Marine bacterial prodigiosin as dye for rubber latex, polymethyl methacrylate sheets and paper. African Journal of Biotechnology 12, 2266-2269 (2013).

44. Kirti, K., Amita, S., Priti, S., Mukesh Kumar, A. \& Jyoti, A. Colorful World of Microbes: Carotenoids and Their Applications, Advances in Biology, 2014, 13 Article ID 837891 (2014).

45. Charkoudian, L. K., Fitzgerald, J. T., Khosla, C. \& Champli, A. In Living Color: Bacterial Pigments as an Untapped Resource in the Classroom and Beyond. PLoS Biol. 8, e1000510 (2010).

46. Heer, K. \& Sharma, S. Microbial pigments as a natural color: A review. Int J. Pharm. Sci. Res. 8, 1913-1922 (2017).

47. Duffose, L. Microbial production of food grade pigments, food grade pigments. Food Technol. Biotechnol. 44, 313-321 (2006).

48. Jagannadham, M. V., Rao, V. J. \& Shivaji, S. The major carotenoid pigment of a psychrotrophic Micrococcus roseus strain: Purification, structure, and interaction with synthetic membranes. Journal of Bacteriology 173, 7911-7917 (1991).

49. Liu, G. Y. \& Nizet, V. Color me bad: Microbial pigments as virulence factors. Trends Microbe. 17, 406-413 (2009).

50. Hall, S. et al. Cellular Effects of Pyocyanin, a Secreted Virulence Factor of Pseudomonas aeruginosa. Toxin. 8, 236 (2016).

51. Noto, M. J., Burns, W. J., Beavers, W. N. \& Skaar, E. P. Mechanisms of Pyocyanin Toxicity and Genetic Determinants of Resistance in Staphylococcus aureus. J. Bacteriol. 199, e00221-17 (2017).

52. Priyaja, P., Jayesh, P., Philip, R. \& Singh, I. S. B. Pyocyanin induced in vitro oxidative damage and its toxicity level in human, fish and insect cell lines for its selective biological applications. Cytotechnology. 68, 143-155 (2016).

53. Joshi, S. M., De Britto, S., Jogaiah, S. \& Ito, S.-i Mycogenic selenium nanoparticles as potential new generation broad spectrum antifungal molecules. Biomolecules 9, 419 (2019).

\section{Acknowledgements}

The authors are thankful for use of the facilities of the Laboratory of Plant Healthcare and Diagnostics, provided by the Post Graduate Department of Studies in Biotechnology and Microbiology, Karnatak University, Dharwad. Also, extend thanks for the Laboratory facilities of Division of Biological Sciences, School of Science and Technology, The University of Goroka, Goroka.

\section{Author contributions}

Proposed the experiment: S.J. \& S.-i. Ito. Bench work of the experiments: S.DB., T.D.G. \& P.S. Examined the data: S.J., L.S. and S.-i. Ito. Contributed chemicals/consumables: S.J. and S.-i. Ito. Writing of the manuscript: S.J., S.DB. and S.-i. Ito. Preparation of Figures/Graphs: S.J. and P.S. All the authors read and approved the manuscript. 


\section{Competing interests}

The authors declare no competing interests.

\section{Additional information}

Supplementary information is available for this paper at https://doi.org/10.1038/s41598-020-58335-6.

Correspondence and requests for materials should be addressed to S.J. or S.-i.I.

Reprints and permissions information is available at www.nature.com/reprints.

Publisher's note Springer Nature remains neutral with regard to jurisdictional claims in published maps and institutional affiliations.

(c) (1) Open Access This article is licensed under a Creative Commons Attribution 4.0 International License, which permits use, sharing, adaptation, distribution and reproduction in any medium or format, as long as you give appropriate credit to the original author(s) and the source, provide a link to the Creative Commons license, and indicate if changes were made. The images or other third party material in this article are included in the article's Creative Commons license, unless indicated otherwise in a credit line to the material. If material is not included in the article's Creative Commons license and your intended use is not permitted by statutory regulation or exceeds the permitted use, you will need to obtain permission directly from the copyright holder. To view a copy of this license, visit http://creativecommons.org/licenses/by/4.0/.

(C) The Author(s) 2020 